\title{
Design of abdominal retractor
}

\author{
Cambal $\mathrm{M}^{1}$, Hucko $\mathrm{B}^{2}$, Zemanova $\mathrm{M}^{1}$, Cekan $\mathrm{M}^{2}$, Horvat $\mathrm{F}^{2}$, Chlebo $\mathrm{O}^{2}$, Bachraty $\mathrm{M}^{2}$, \\ Hrbaty $\mathrm{B}^{1}$, Labas $\mathrm{P}^{1}$ \\ 1st Surgery Clinic, Faculty of Medicine, Comenius University in Bratislava, Bratislava, Slovakia. \\ cambalma@gmail.com
}

\begin{abstract}
INTRODUCTION: The purpose of this paper is to present the development and design of an abdominal retractor which allows a single person to perform operations and the fixation of the operation instruments can be done with one hand. The additional devices make the operation more comfortable for surgeons. METHODS: Conventional measuring devices have been designed and applied for determining axial forces in a surgeon's forearm during operations. The same forces must be transmitted by the frame of the retractor. Thus a simple truss structure of a retractor was done. Several types of fixations have been proposed and tested using the rapid prototyping. Finally, the abdominal retractor was manufactured from stainless steel. RESULTS: The simple-to-use abdominal retractor was built. The standard surgery instruments were modified due to the fixation system of the frame. A wide variety of additional useful devices, such as a lamp, video camera etc., were also proposed.

CONCLUSION: The present abdominal retractor is user-friendly and all components are easily sterilized by conventional methods (Fig. 7, Ref. 6). Text in PDF www.elis.sk.

KEY WORDS: abdominal retractor, stainless steel retractor, standard surger, fixation system of the frame, lamp, video camera, conventional methods.
\end{abstract}

\section{Introduction}

The incentive for a new design of an abdominal retractor was underpinned by the price of the commercial products and their relatively complicated positioning of instruments on the retractor frame. Therefore, we decided to simplify the structure of the proposed functional retractor for operations in the abdominal cavity to replace the secondary surgeon during surgery. The variability and flexibility of the new retractor allow to carry out all operations in the abdomen. The precise positioning of the frame's arms and tool kits' retractor will be possible with one hand. The new design requires a modification of standard instruments to change the handle due to the positioning devices.

The price of the retractor depends on the materials and technologies used to manufacture it. We tried to make it as simple as possible to enable them to be intuitively fixed on the operating bed without any special instructions. This means that it can be easily sterilized without special sterilization requirements. Another re-

${ }^{1}$ The 1st Surgery Clinic, Faculty of Medicine, Comenius University in Bratislava, Bratislava, Slovakia, and ${ }^{2}$ Institute of Applied Mechanics and Mechatronics, Faculty of Mechanical Engineering, Slovak University of Technology in Bratislava, Bratislava, Slovakia

Address for correspondence: M. Cambal, MD, PhD, 1st Surgery Clinic, Faculty of Medicine, Comenius University in Bratislava, Mickewiczova 13, SK-813 69 Bratislava, Slovakia.

Acknowledgement: The authors would like to express their gratitude for the financial support of APVV-15-0757 project. quirement was to minimize the number of components from which the retractor should be assembled.

This paper presents the process of the successful retractor design using up-to-date technologies.

\section{Materials and method}

The basic requirements on the retractor design are stiffness and its size. To reduce material requirements, we had to get information about the load. Therefore, the practical load measurement acting on the surgeon's arm was the first step in the design of the new ab-

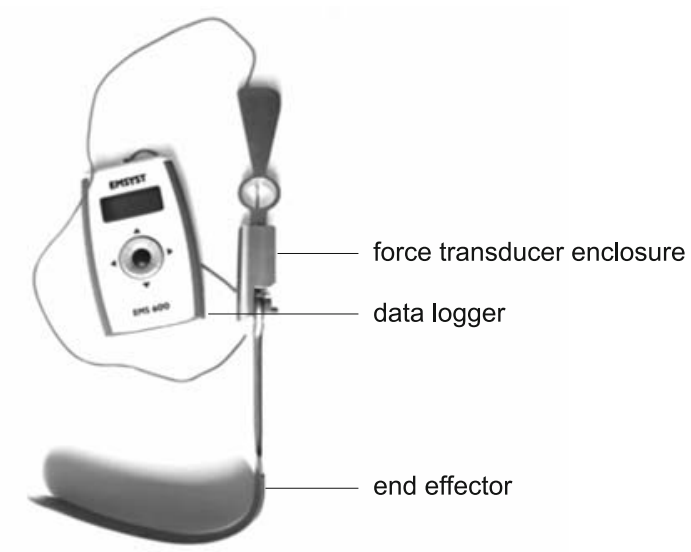

Fig. 1. Modification of the deep surgery retractor for incorporating a force transducer. 

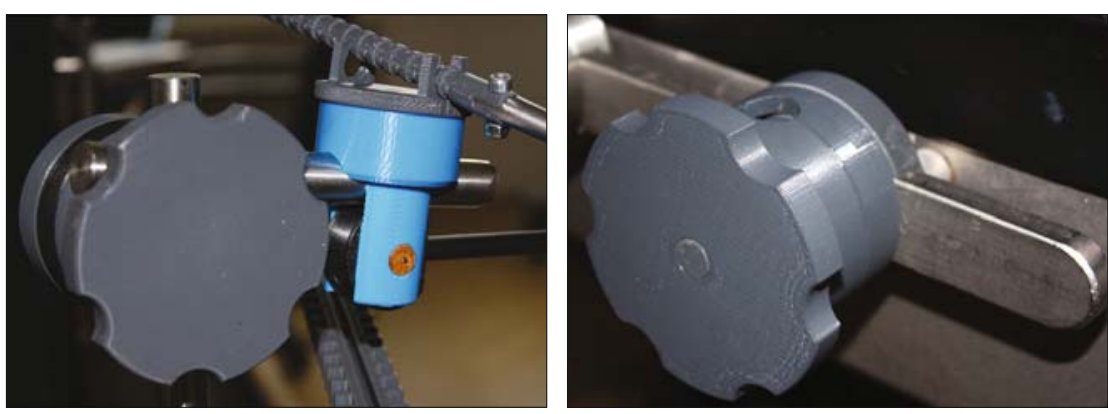

Fig. 2. Fixation elements made of ABS material.

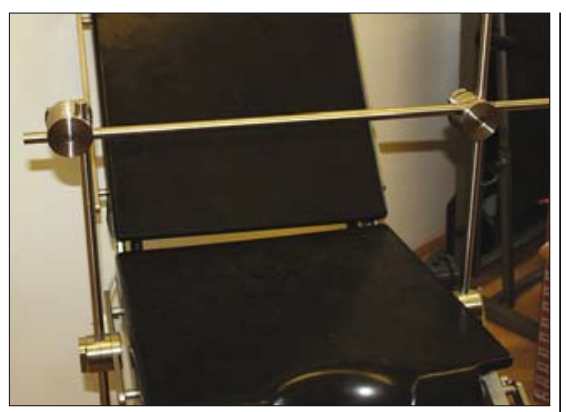

Fig. 3. Proposed frame of retractor.

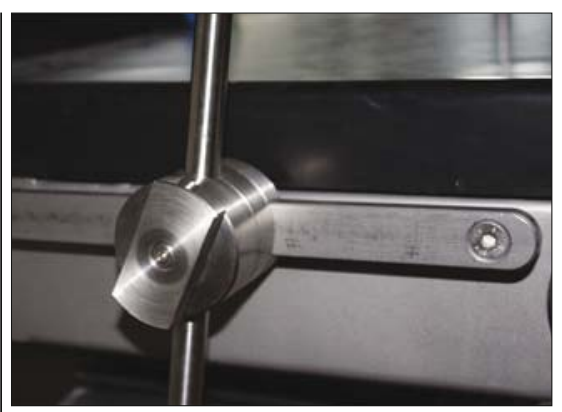

Fig. 4. Fixation on DIN rail.

remote data logger (EMS600) recording at a rate of $10 \mathrm{~Hz}$ over $100 \mathrm{sec}$. intervals.

From data obtained from the above mentioned measurements, a standard statistical analysis was performed resulting in an average loading of $6.06 \mathrm{~N}$ with a maximum measured value of $40 \mathrm{~N}$, with a standard deviation of $5.07 \mathrm{~N}$ and the coefficient of variation of $83.7 \%$. This maximum measured force corresponds to the maximum pulling force that female fingers can produce (2). Due to the balance between the external measured force (holding force) and the muscle tension, we can predict that if the static external force exerts longer than usual relaxation time without any movement then we will assume that isometric conditions are satisfied. Any movement of fingers will be registered by the sensitive force transducer.

We used a rapid prototyping techno$\operatorname{logy}(4,5)$ to design the positioning and fixation parts as well as the entire retractor frame with the necessary modifications of surgical instruments. We have developed

dominal retractor. We applied our proposed methodology in (1) for this measurement. Thus, we got the loading which should be also applied to the retractor frame that will replace the surgeon. It was decided that the Mikulicz and Fritsch deep surgery retractors (Fig. 1), would be modified to incorporate a miniature, high-precision force transducer which would record data during surgical intervention. The force transducer was strategically mounted to measure axial loading between the end effector and handle. The chosen transducer has an effective measuring range of $2-200 \mathrm{~N}$ and is powered by a several variants that were subsequently tested by surgeons on models made of ABS materials in a real size (Fig. 2). The models were placed on the operating bed so that surgeons could try handling the retractor and its components. The aim of the presented tests were functional testing, handheld handling, ergonomics and suitability. Based on their comments, the positioning devices were modified, especially the fixation parts. Subsequently, a fully functional aluminium model was manufactured. This model seemed to be more realistic. Again, this model was subject to functional tests.

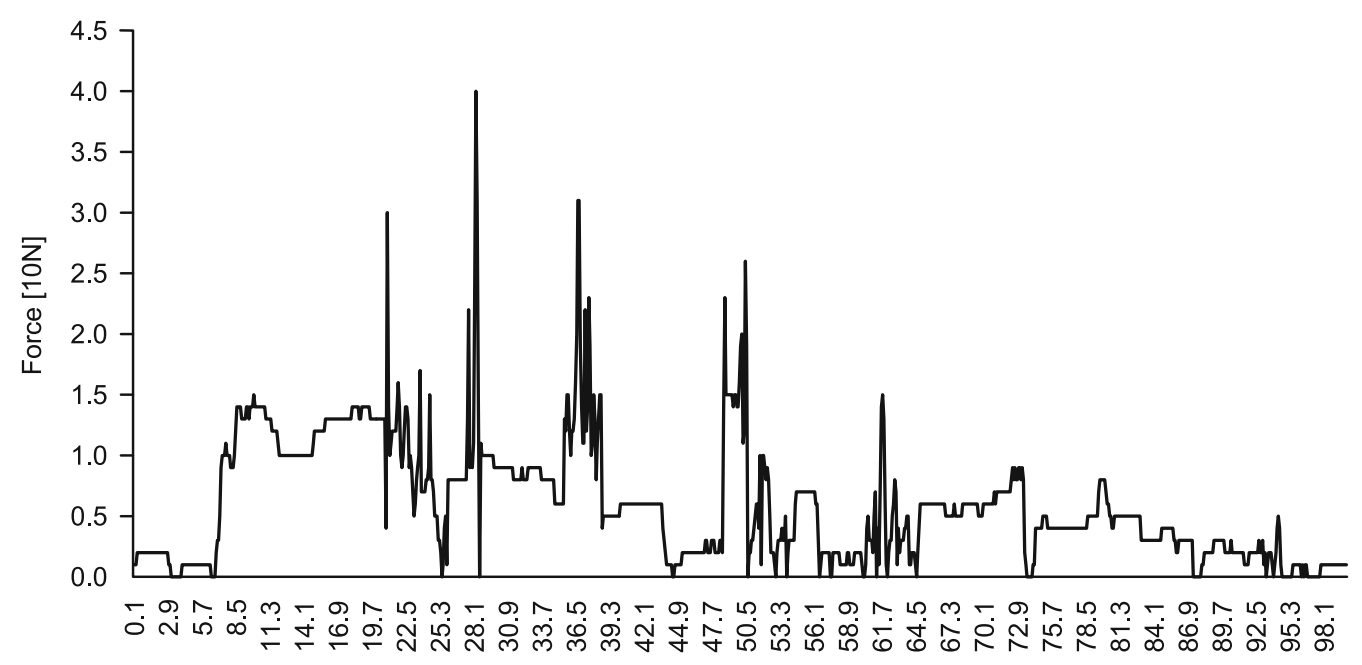

Time [s]

Fig. 5. Axial force measured between the blade and handle of the deep surgery retractor. 

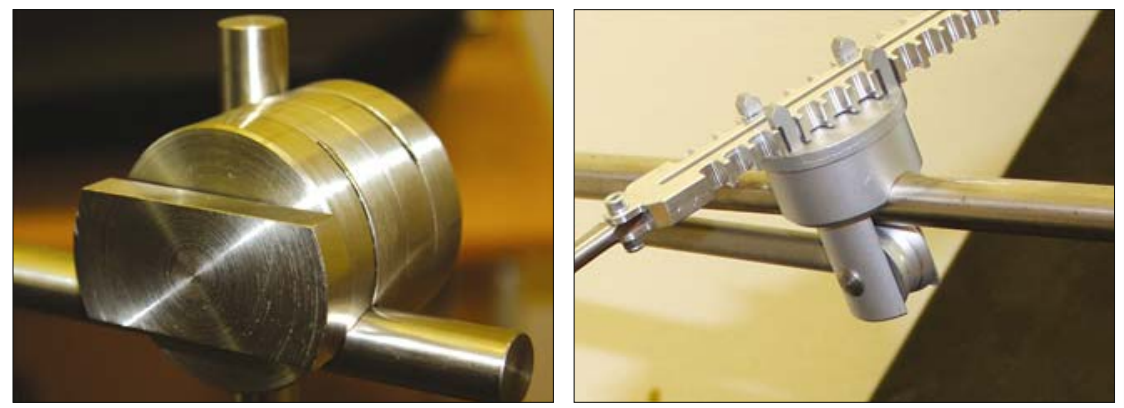

Fig. 6. Different fixation parts: frame and instruments.

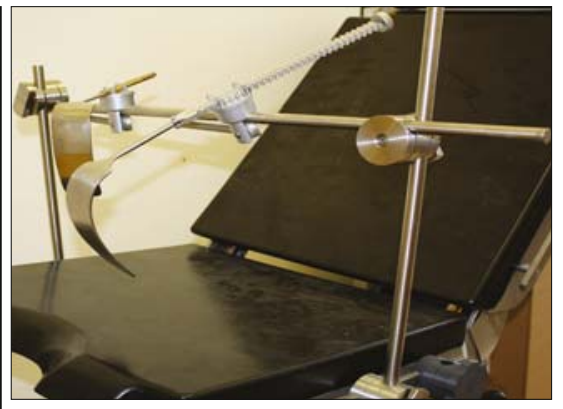

Fig. 7. Final design.

\section{Results}

The logical step was to design the simplest structure of the retractor frame. The proposed frame consists of three straight rods: two vertical rods and one horizontal rod (Fig. 3). Each vertical rod is fixed on the lateral DIN rail of operation bed (Fig. 4). The material of the rod is stainless steel recommended by the surgeons' standards. This steel is highly resistant to conventional sterilizing agents. The rod size, from which the retractor frame is built, was designed based on the maximum applied load. The maximum applied axial force is $40 \mathrm{~N}$ multiplied by a factor of safety. The factor of safety for loading shown in Figure 5 was selected as 3.0. Thus, the maximum applied force is $120 \mathrm{~N}$. Subsequently, the size of the rod is determined to be $16 \mathrm{~mm}$ (diameter).

All fixation parts are designed as friction joints with screws or eccentric cam (Fig. 6). Then the final product is presented in Figure 7 (6).

\section{Discussion}

The presented abdominal retractor was built with the collaboration of medical doctors and researches of two universities. The results form an excellent basis for a future collaboration for improving the medical care and working conditions of surgeons.

\section{References}

1. Hučko B, Čekan M, Horvát F, Chlebo O, Bachratý M, Čambal M. Measurement of abdominal retractor loading and its effects on the surgeons arm. Interdisciplin J Engineer Sci 2018; 6: 60-63.

2. Astin AD. Finger force capability: measurement and prediction using anthropometric and myoelectric measures, MSc. Thesis submitted to the Virginia Polytechnic Institute and State University, Blacksburg, Virginia, 1999.

3. Čekan M, Hučko B, Horvát F, Bachratý M, Čambal M. Investigation of polymer based abdominal retractor according to existing design parameters. Appl Comput Mechan 2019; 19.

4. Kamrani AK, Nasr EA. Engineering Design and Rapid Prototyping. Springer 2010.

5. Chua ChK, Leong KF, Lim SCH. Rapid Prototyping: Principles and Applications, World Scientific 2010.

6. Čambal M, Hučko B, Vrtík L, Zemanová M, Hrbatý B, Škoda A, Labaš P. Abdominálny retraktor. In: 72. chirurgický deň Kostlivého: Súčasné trendy v chirurgii gastrointestinálneho traktu. Bratislava: Univerzita Komenského v Bratislave, 2018, s. 34.

Received November 3, 2019. Accepted February 7, 2020. 